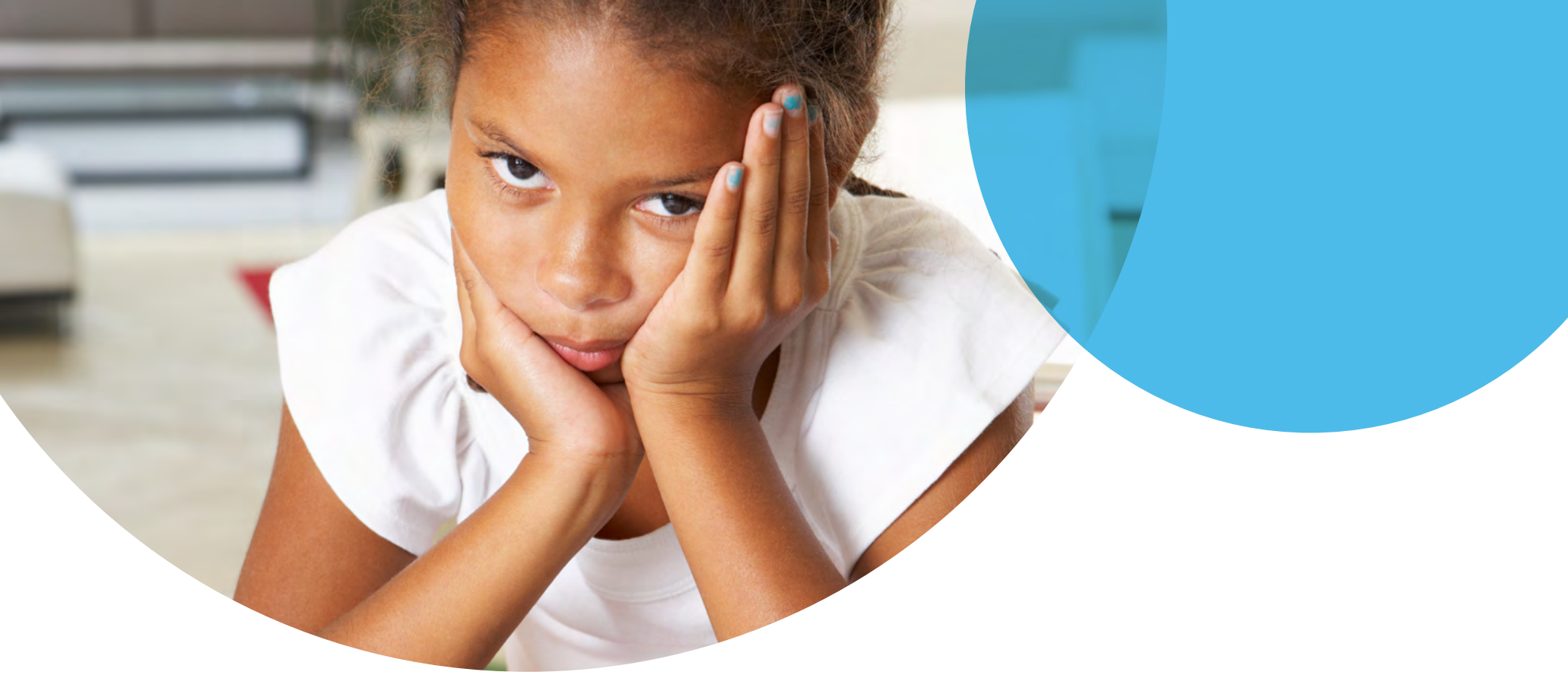

\title{
Do we remember more when learning before bedtime?
}

\author{
By Dr. Jessica Edwards
}

Researchers at the University of York have found that children with poor reading comprehension have a lower capacity for vocabulary learning than children with good comprehension. This relative learning impairment is apparent even when new vocabulary is not reliant on text comprehension. Despite these difficulties, however, poor comprehenders seem to have a good ability to retain new knowledge once it is learnt.

The study by Emma James et al. involved tracking the retention of new words taught at different times of the day in 15 children with good and 15 children with poor comprehension aged 8-12-years-old. The children were taught 12 words either early in the morning or as close as possible to bedtime, and were then tested immediately, $12-\mathrm{h}$ and 24 -h later. As a control, the children also completed a spatial memory task to test whether any weaknesses were specific to linguistic information processing.

The team also found that learning close to bedtime might benefit long-term memory in both groups of children. Specifically, the recall of word-forms seemed to improve over-sleep and post-sleep wake and had long-lasting benefits up to 1-2 months later.

"These preliminary findings suggest that this bedtime benefit might be particularly helpful for children with a weak vocabulary", explains James. "Understanding whether we can time learning to improve retention of new vocabulary is an important direction for new research - especially given that literacy activities usually take place in morning schooling". Given that children with poor comprehension had good retention of new knowledge, James et al. speculate that efforts to improve initial learning could have long-lasting effects.

\section{Referring to:}

James, E., Gaskell, M.G. \&

Henderson, L.M. (2020), Sleep-

dependent consolidation in children with comprehension and vocabulary weaknesses: it'll be alright on the night? J. Child Psychol. Psychiatr. doi: 10.111/ jcpp.13253. 